\title{
CIDADANIA, EXCLUSÃO E DIREITOS HUMANOS: LIMITES E DESAFIOS DA CIDADANIA CONCRETA
}

Alexandre Medeiros de Araújo ${ }^{1}$

\section{RESUMO}

Este projeto de extensão foi motivado em função da urgente necessidade de se resgatar o papel da educação em seu compromisso com a construção da Cidadania. O objetivo do projeto consistiu em levar os alunos ao reconhecimento dos principais desafios e limites da Cidadania atual a partir dos casos concretos de exclusão do seu exercício. $O$ método adotado foi o levantamento e análise dos principais casos de exclusão contrastando com aquilo que a Declaração Universal dos Direitos Humanos e a Constituição Federal do Brasil proclamam, ou seja, apresentando as contradições entre a lei e os casos concretos visíveis no dia a dia da comunidade local. Ao fazer isso, o projeto tem sensibilizado os alunos para o exercício de sua Cidadania por meio da mudança do olhar de cada um acerca das desigualdades e exclusões sociais, agregando valores e conscientizando-os a respeito da promoção da igualdade, da luta pelo acesso amplo à justiça e à segurança, pelo sentido de responsabilidade e pelo valor da solidariedade.

Palavras-chave: Exclusão. Cidadania. Justiça.

\section{INTRODUÇÃO}

\subsection{Apresentação}

Segundo a UNESCO (Organização das Nações Unidas para a Educação, ciência e cultura), uma preocupação crescente e um debate a respeito dos Direitos Humanos, bem como as ações técnicas e políticas relacionadas a esse tema, "têm mobilizado a mídia nacional e elevado a consciência da sociedade brasileira sobre assuntos que são extremamente importantes para a promoção da Cidadania e para o respeito aos direitos humanos" (Site da UNESCO). No entanto, a despeito de todos os esforços na divulgação do que representa essa universalidade e indivisibilidade dos Direitos humanos, quando se trata da prática concreta da Cidadania, muitos grupos continuam a encontrar grandes dificuldades no exercício de sua Cidadania e, por isso mesmo, na realização de seus direitos fundamentais. Nesse sentido, "a lei, para se aplicar a todos, deve ser genérica. Mas a lei, para se aplicar a cada um dos casos, deve ser permanentemente questionada pela prática" (VALLE, 2000, p. 29).

Com a finalidade de promover a construção de um sentido concreto da Cidadania, o presente projeto de extensão se justifica em função da 
necessidade de se pensar os "limites e os desafios" da Cidadania por meio do questionamento da prática que envolve os casos particulares de exclusão, uma vez que a lei, por sua extrema generalidade, não distingue.

Apesar de haver um crescente debate a respeito dos Direitos Humanos que asseguraria, em termos legais, a "igualdade sem reservas" a todos os indivíduos, os "limites e os desafios" da Cidadania só se tornam visíveis quando nos voltamos para os casos concretos de exclusão: os deficientes físicos, os portadores de necessidades especiais, os negros, os homossexuais, os índios, os idosos... .

Ao contemplarmos esses casos concretos de injustiça e exclusão, somos levados a refletir que, para a realização plena da Cidadania, não basta apenas a proclamação dos direitos universais e da lei como o Neoliberalismo nos quer fazer acreditar. Tal proclamação, sem ser acompanhada de um contínuo questionamento sobre os casos concretos de exclusão da Cidadania, escamoteia as contradições, injustiças e preconceitos, ocasionando, assim, todo tipo de exclusão.

Em função de sua amplitude genérica, a lei - que proclama a igualdade irrestrita de todos os seres humanos - não leva em conta os casos particulares de exclusão, bem como os desafios sociais, históricos e culturais que se interpõem como obstáculos à realização da Cidadania plena. É preciso, desse modo, uma maior discussão, análise e reflexão sobre os limites da Cidadania concreta a partir dos sujeitos e grupos excluídos da sociedade, chamando à atenção para o papel a ser desempenhado na Escola Pública que é a formação cidadã dos seus alunos em vista de promover a realização da Cidadania.

O sentido do que é a Cidadania pressupõe, portanto, que se leve em conta a sua construção concreta em face aos desafios e limites da prática cotidiana para a construção de uma cultura Cidadã garantindo a igualdade no que diz respeito à justiça social e a não exclusão dos diferentes, dando a esses as condições efetivas de igualdade e possibilidade de pleno desenvolvimento de uma vida digna.

\section{OBJETIVOS}

O objetivo desse projeto de extensão é levar os alunos ao reconhecimento dos principais desafios e limites que envolvem a prática concreta do exercício da Cidadania, sobretudo, a partir dos casos de exclusão social e no que diz respeito ao reconhecimento das diversidades à luz dos princípios contidos na Declaração Universal dos Direitos Humanos (1948) e da Constituição Federal da República do Brasil (1988), de modo a fomentar nos alunos posturas e atitudes adequadas para o exercício de práticas Cidadãs e pela formulação de propostas que visem acabar com as formas de exclusão e atentado aos direitos fundamentais do ser humano.

\section{METODOLOGIA}

a) O primeiro passo é a apresentação dos temas correspondentes aos casos concretos de exclusão da Cidadania como: Diversidade e cultura Afro-indígena; Igualdade de gênero; Identidade de gênero e orientação sexual; Inclusão social (Inclusão de pessoas portadoras de necessidades especiais, dos idosos...);

b) O segundo passo é o estudo da Declaração Universal dos Direitos Humanos e da Constituição federal da República do Brasil sobre os direitos dos Cidadãos contrastando com a visualização dos casos concretos de exclusão da Cidadania;

c) O terceiro passo é o levantamento de dados sobre a exclusão dos grupos citados acima, nas escolas, no próprio Instituto Federal e na Cidade de Santa Cruz no RN;

d) O quarto passo é o diagnóstico das principais causas de exclusão desses grupos a partir da visualização de casos e análise de dados e entrevistas com representantes desses grupos e associações representantes dos interesses desses grupos;

e) O quinto passo é a confecção de materiais (vídeos e pôsteres) retratando esses casos de exclusão e proposta de atitudes e ações concretas individuais e coletivas, implementação de ações nas escolas para a formação da cidadania e elaboração de propostas de políticas públicas para se acabar com essas exclusões;

g) O sexto passo é a apresentação do material confeccionado para toda a comunidade escolar e para a comunidade local.

\section{DESENVOLVIMENTO}

Tem se observado na execução do projeto o empenho dos alunos em identificar os casos e as causas da exclusão na comunidade onde vivem e na escola. Muitos são os materiais que confirmam nossa hipótese de trabalho e que precisam urgentemente de um olhar de toda a 
comunidade escolar. Alguns casos de exclusão têm sido identificados na própria escola e discutidos em conselho de classe, como a exclusão da diversidade sexual. Esses casos levaram a equipe pedagógica a pensar em um núcleo de oficinas sobre os Direitos Humanos no qual, a cada semana, se discutiria sobre um determinado tema com palestrantes externos ao Instituto. É visível como os grupos têm se empenhado em registrar os casos concretos de exclusão na comunidade onde vivem e sua conscientização de que algo precisa urgentemente ser feito. Os grupos se reúnem semanalmente, discutem a partir dos dados coletados por eles mesmos, apresentam alternativas para a busca da erradicação das exclusões as quais identificaram, propondo, assim, caminhos concretos para a cidadania daqueles grupos excluídos.

\section{CONCLUSÕES}

O ganho maior que esperamos obter ao fim desse projeto consiste, antes de mais nada, no preparo dos alunos para o exercício de sua cidadania como agentes transformadores, não só no ambiente escolar, mas, sobretudo, na comunidade onde vivem. O projeto tem chamado à atenção para o papel da escola na formação de uma cultura da Cidadania, que, como se tem observado, não se realiza pela memorização de leis e declarações que, ao afirmar uma igualdade que não se realiza de fato, acaba por esconder as contradições que são causas da exclusão.

Nesse sentido, foi preciso encarar de frente os limites e desafios dessa cidadania proclamada na lei mas nunca efetivamente realizada na prática da vida. Foi preciso se voltar para os casos concretos a fim de observarmos as exclusões produzidas pela contradição de um sistema que descarta os que não produzem: os idosos, os portadores de necessidades especiais, os deficientes físicos. A "igualdade" afirmada pelo Neoliberalismo é aquela na qual os sujeitos têm o poder de consumo e descarta aqueles que não podem produzir e, por isso mesmo, consumir. $\mathrm{O}$ desafio da escola, nesse sentido, é o de combater as exclusões pela promoção de cultura na qual os valores da solidariedade, do respeito às diferenças, da inclusão social sejam postos como princípios mais básicos.

Esse projeto de extensão tem mostrado que a escola pode e deve cumprir seu papel de formação para cidadania, na medida em que tem levado os alunos a se darem conta das enormes exclusões presentes no dia a dia, identificando as suas causas e formando-os para combatêlas. Nesse sentido, o projeto tem possibilitado a tomada de consciência do poder transformador da educação para a realização da cidadania, e, por isso mesmo, do combate à exclusão, a partir das condições de possibilidades que são as nossas, no lugar onde nos encontramos, na nossa escola, na nossa comunidade e na nossa cidade. Concluímos que, somente levando em conta a exclusão desses casos concretos, a escola pode cumprir seu papel para a sociedade, que é a construção da Cidadania, agregando, desse modo, os valores imprescindíveis para a democracia.

\section{REFERÊNCIAS}

CANDAU, Vera Maria. Multiculturalismo e Direitos Humanos, In: Brasil: Construindo a Cidadania: desafios para o século XXI. Recife: Rede Brasileira de Educação em Direitos Humanos, 2001. p. 4348.

. Educação em Direitos

Humanos e Diferenças Culturais: Questões e Buscas. In: Revista Múltiplas Leituras, V. 2, n. 1, Jan/Jun. 2009, p. 65-82.

Diferenças Culturais, Cotidiano Escolar e Práticas Pedagógicas. In: Currículo sem Fronteiras, v. 11, n.2, Jul/Dez. 2011, pp. 240-255.

ONU/UNESCO. Plano de ação: Programa Mundial para Educação em Direitos Humanos, primeira e segunda fases. Disponível em http://www. onu.org.br/unesco-disponibiliza-programamundial-de-educacao-em-direitos-humanos-emportugues/. Acesso em 06 Julho de 2014.

SANTOS, Boaventura de Souza. Uma concepção multicultural dos direitos humanos. In: Lua Nova. Revista de Cultura e Política. № 39. São Paulo: CEDEC, 1997, p. 105-124.

VALLE, Lílian do Valle, O Mesmo e o Outro da Cidadania. Rio de Janeiro: DP\&A, 2000, p. 29. 